\title{
An investigation of the prevalence of stress among graduate and post- graduate Indian students during COVID 19 pandemic by means of factor analysis
}

\author{
Anita P Bobade \\ Kasturi R Naik \\ DES's NMITD, University of Mumbai, India
}

Keywords

Emotional resilience, COVID 19, stress management, pandemic, HEI, academic excellence

\begin{abstract}
Objective: Since December 2019, the COVID-19 pandemic has posed a considerable threat with its associated high mortality, infection, and hazard of physical, mental, emotional, financial, and spiritual stress (WHO, 2020). A large number of students are affected due to a chronic break from classroom academic activities, the pressure of being hired for an internship or final placement and staying at home. The main focus of this learning is to know the stressors of graduate and post-graduate Indian students and their major hurdles during the COVID-19 lockdown. Further, the study aims to facilitate a proposed model of training, by combining 7 psychosocial variables of emotional resilience which might empower the students to cater to stressors and improve personal, academic, and professional effectiveness (Chen et.al, 2020; Horesh et.al, 2020)

Methods: Using a convenience method, an internet survey of the 6-item COVID-19 Student Stress Questionnaire (CSSQ) (modified version Zurlo et.al, 2020) was conducted on students across India. together with their demographic details, the participants also reported their study patterns and challenges during their confinement period. The statistical scores for the responses were calculated and also the demographic variables analyzed using the factor analysis technique. (Ahorsu et.al,2020)

Findings, discussion, and implications: The findings suggest that self-awareness, selfregulation, mental agility, optimism, self-efficacy, sense of belonging and psychological safety may be the important emotional resilience to be developed among the Indian students to cope with physical, mental, emotional, financial, and spiritual stressors confronted by them during COVID 19 pandemic to increase personal and professional effectiveness (Maria et.al, 2020, Zurlo et.al. 2017)

Conclusion: The study has several practical implications for counseling psychologists, academicians, parents, life coaches handling youth and mental health workers related to the graduate and post-graduate education sector (Taylor et.al, 2020; Sahu et.al, 2020).
\end{abstract}

\section{Introduction}

COVID-19 outbreak had impacted mankind phenomenally. The subsequent lockdown and social distancing affected youth considerably, especially as the academic institutions operated online, social gatherings were not permitted globally. Further this lockdown had economic implications and loss of job opportunities, affected the emotional security of youths.

The COVID-19 pandemic has created the most severe disruption to global education systems in history. India's higher education system is the world's third largest in terms of students, next to China and the United States. In future, India will be one of the largest education hubs. In India over 39,000 Colleges and over 18000 Post Graduate Institutions of Higher Education Institution (HEI) cater to 27.5 million undergraduate and over four million postgraduates in India. Over 3.4 million Indian students enrolled in higher education would be affected psychologically due to the Covid19 Pandemic, (Margaritis et.al, 2020).

The pandemic and the lockdown, self-quarantine, social distancing, and self-isolation, all have had a negative impact on mental health. Concerns about one's own health and that of their beloved ones (particularly elderly or suffering from any physical illness), as well as uncertainty about the future are some of the signs of mental illness. Youths also experienced a range of emotions including distress, grief, insomnia, anger, depression and fear of the future. It also mentioned mood swing, emotional imbalance, irritability and fatigue. ( Fiorillo A, Gorwood P, 2020) 
According to the transactional model of stress coping developed by Lazarus and Folkman (1984), involves both intellectual and behavioural retorts that individuals use in an effort to manage internal and/or external stressors. Stress coping mechanism depends on the constant interaction between individual factors (e.g., age, gender) and situational factors, thus requiring needing into consideration specificities of target populations.

Ministry of HRD, Government of India, have given a platform to address the emerging needs and concerns and the psychological stress and mental wellbeing of the youths from diverse backgrounds, needs and aspirations from all across India, by launching a National Toll-Free No and a website, "Manodarpan" to monitor and promote mental health issues and concerns and give psychological support for mental wellbeing during Covid19.

As per the recent survey conducted by WHO (2020), the young population is at lesser risk in term of developing Covid 19 or related physical wellbeing, however it has disrupted their access to education and employment. Further, being unemployed at a young age can have long-lasting "scarring effects" regarding their career path and future earnings. (Heckman and Borjas, 1980; Ellwood, 1982 as cited in OECD Report, 2020). Further as regards India, job loss among youth will continue throughout 2020 and could result in youth unemployment rates doubling. As per the report of ILO (April 2020), over 6 million youths in India will lose jobs and the rate of unemployment would touch around $30 \%$ by 2021 .

During the lockdown, youth spent extra time on the social media, which further intensified their stress levels and led to depression, anxiety, body image, and poor sleep. (Hamilton, J et al;2020). Lockdown also affected physical mobility and increase sedentary behaviour among youth. Physical activity is essential for a healthy, active lifestyle which in turn affects the value of life of the youth.

The study documents the mental health of youth from University of Mumbai - undergraduate, postgraduate and working executive, to assess the perceived stress of students during Covid19. The study adapted the COVID-19 Student Stress Questionnaire (CSSQ), which has been empirically tested on Italian University students and is cited. (Zurlo et al; 2020) .

\section{Literature review}

Covid-19 which is probably one of the worst pandemics in the history has deep rooted impact globally on various nations, economies and sectors. The consequence of several lockdowns post March 2020 in India too has affected various sectors of Indian economy to its core.

India's higher education system is the third largest in the world, next to the United States and China India is a young country with over 500 million in the age bracket of 5-24 years, which gives it a demographic dividend and provides bright prospects for the education sector (https://www.worldbank.org/en/publication/wdr2020). Every dimension of human existence has been completely shaken by the sudden spread of COVID-19 and subsequent lockdowns after the same. Indian Higher Education Institution (HEI) sector, was no exception which saw sever impact of the pandemic significantly (Jena, 2020).

Over $60 \%$ of young learners across the globe, have been severely affected by this Covid19 pandemic (UNESCO, 2020). Further over 1.1 billion student's educations has been hindered by closure of colleges and universities and emergency remote learning. In India over 30 crore students studying in various schools, colleges and universities were forced to continue their education post lockdown without much of preparation and several restrictions ( The Print,2020)

The main stressors during a pandemic as cited by Zurlo et al;(2020) are the following: risk of contagion (Brooks et al., 2020; Xiang et al., 2020); Social isolation and social exclusion; Their Relationship with their Family; Their Relationship with their Friends; Their Relationship with their Professors; Academic Studies and Related Stress. As cited by Zurlo et al ; (Oct 2020), in a review conducted by Brooks et al. (2020) there was a huge impact on the psychology of the respondents during quarantine periods, chief among them was the dread of contagion, anxiety and frustration related to inadequate supplies of medicines and daily necessities as also inadequate information from the public health authorities, a sense of loneliness, due to loss of socialisation and routine work. Further, Zurlo et al; (2020) state that the lockdown and closure of HEI, led to Fear of Missing Out (FOMO) and deeply impacted the personal and emotional lives of youngsters. 
Further, the youngsters were anxious about their own health and the health of the members of their family. Since there was no physical connect, their relationship with friends and Professors lost the connect and as such were one of the stressors. Online teaching learning posed another stress amongst the youngsters.

It is apparent that the profound psychological and social impacts of the pandemic are inescapable, and it is the need of the hour to take steps in building resilience and coping with such damaging consequences of a pandemic. One of the objectives of the present study was the need for immediate intervention in the form of a training programme to empower the students with emotional resilience. Hence, we introduce the concept.

Fredrickson (1998) define resilience as characterized by the power to retrieve from negative emotional experiences and by flexible adaptation to the dynamic demands of stressful experiences. The term resilience, can be traced to the Latin verb resilire which suggests rebounding or "leap back." Resilience might be a term utilized in several fields originally coming back from ecology; with resilience denoting the flexibleness of an ecosystem to recover or avert harm once disturbed. It is most suited as a psychological response.

Bonanno et.al (2018) projected that resilience is that the flexibility to "maintain a stable equilibrium" it completely was projected that resilience is distinct from recovery that resilience is common. Bonanno reports that resilience is that the foremost frequent or modal outcome in response to adversity.

Additional merely Infurna et al. (2016) have outlined resilience as; "A dynamic method encircling positive adaptation inside the context of significant adversity" (p. 543). Being an active process, resilience throughout this conceptualization is considered by constant amendment, activity, or progress. Resilience is context-specific with a private doubtless being extremely resilient in one context however not in another. (Armstrong et.al, 2011)

The construct of resilience has been studied since the first Nineteen Seventies. Initial analysis throughout this area investigated the thought of resilience in poor and neglected youngsters; noting that not all youngsters exposed to neglect, and financial condition have the identical outcomes. Specifically, some kids grew up and prospered despite the adversity whereas others languished. Initially, these kids were determined as being 'invulnerable' as opposed to resilient (Galatzer, 2018). As at presently the thought was fashioned as being either gift or absent in folks and world as opposition relative and contextualized. As analysis a lot of progressed it became seeming that resilience was every relative and contextualized, consequentially the term invulnerable lost favor. (Davidson, 2000)

For the purpose of this research resilience is defined as the ability to recover from adversity and also the flexibility to grow from challenges (Lei et.al, 2020)

A person's capacity to bounce back, once resilience is determined by one's psychological makeup, one's social relationships and interactions, which are called psychosocial aspects of resilience for this study (Dr. Karen and others, 2003). It encompasses the learnings from all the four waves of research related to resilience. We further document the seven variables of Emotional Resilience which include Self-awareness, Self-regulation, Mental agility, Optimism, Self-efficacy, Connection, Positive institutions

These aspects are going to be discussed in detail within the implications of the study

\section{Research Objectives}

The objectives of the present study:

The study aims to assess the impact of the COVID-19 outbreak on the mental health of the youths of University of Mumbai, India.

The study aims to study the stressors which impacts the mental health of the youths of University of Mumbai, India.

The study documents various measures of the Government of India taken for motivating the youth for a positive mindset and the proposed model of training for these youths to build and nurture their emotional resilience.

Based on the above, the research questions for the present study are summarized as below:

To study, the impact of the COVID-19 outbreak on the mental health of the youths of University of Mumbai, India. 
To outline, the stressors which impacts the mental health of the youths of University of Mumbai, India.

To describe the various measures of the Government of India taken for motivating the youth for a positive mindset and the proposed model of training for these youths to build and nurture their emotional resilience.

\section{Questionnaire Focal Construct:}

Construct validity is established empirically to prove that a survey differentiates between people who do and do not have certain features. Globally, COVID-19-related control measures levied lockdown of workplaces as well as HEI. This lockdown, social distancing, had a profound impact on personal and emotional lives of youths, who experienced doubt, state of mind of seclusion, and sense of "losses" in terms of drive, sense, and self-worth (Williams et al., 2020).

Zurlo et al. COVID-19 Student Stress Questionnaire, (Oct 2020). It is a 7-item COVID-19 Student Stress Questionnaire (CSSQ), a dimension tool to assess COVID-19-related sources of stress among university students, established by Zurlo et al; ( Oct 2020) was used. CSSQ was earlier and authenticated with 514 Italian university students through Exploratory Factor Analysis (EFA) in the study conducted by Zurlo et al; (Oct,2020) which focused on assessment of the sources of stress associated with Covid 19 pandemic lockdown among university students, namely the COVID-19 Student Stress Questionnaire (CSSQ).

Method : Participants : The youths who were sent the questionnaires were grouped in three categories : 1) Undergraduate Students of University of Mumbai 2) Post Graduate Students of University of Mumbai 3) New Recruits of University of Mumbai who have less than 2 year's work experience.

A total of 108 youths in the age group of 18- 25 from the city of Mumbai, who were undergraduate, postgraduate, Alumni of University of Mumbai participated in this survey.

\section{Research Methodology}

The research design focuses on quantitative research study by means of using statistical analysis tool factor analysis to determine important physical, financial, emotional, mental, and spiritual stressors which graduate and post-graduate students might be dealing with COVID 19 pandemic (Zurlo et al. COVID-19 Student Stress Questionnaire). In this study use is created of form and informal interviews, for gathering the first information and secondary information is gathered by means that of printed and unpublished paper and electronic sources like journals, newspaper, articles etc (Conway, et.al ;2006). For the aim of primary information collection form was circulated to a hundred graduate and post graduate students from Mumbai using convenience sampling technique. For the analysis underneath study the tool used for information analysis was correlational analysis. The Cronbach a value is among permissible limits to hold factor analysis.

$\mathrm{H}_{0}$ : There is no internal consistency and reliability among the variables selected in the study for conducting factor analysis focusing on important stressors which graduate and post-graduate students might be dealing with COVID 19 pandemic

$\mathrm{H}_{1}$ : There is an internal consistency and reliability among the variables selected in the study for conducting factor analysis focusing on important stressors which graduate and post-graduate students might be dealing with COVID 19 pandemic

From the study of the literature, following parameters are considered as important with respect to stressors which graduate and post-graduate students might be dealing with COVID 19 pandemic:

Contagion Risk

Social Isolation

Relationship with family

Relationship with friends

Relationship with professors

Academic study stress

Data Analysis

Multivariate statistical analysis tool factor analysis is used to determine the important stressors which graduate and post-graduate students might be dealing with COVID 19 pandemic 
Correlation Matrix ${ }^{a}$

\begin{tabular}{|c|c|c|c|c|c|c|}
\hline & & Contagion & $\begin{array}{c}\text { Sociallsolatio } \\
n\end{array}$ & relatives & friends & Professors \\
\hline Correlation & $\begin{array}{l}\text { Contagion } \\
\text { Sociallsolation } \\
\text { relatives } \\
\text { friends } \\
\text { Professors }\end{array}$ & $\begin{array}{r}1.000 \\
.566 \\
-.060 \\
.095 \\
.251\end{array}$ & $\begin{array}{r}.566 \\
1.000 \\
.012 \\
-.043 \\
.069\end{array}$ & $\begin{array}{r}-.060 \\
.012 \\
1.000 \\
.734 \\
.377\end{array}$ & $\begin{array}{r}.095 \\
-.043 \\
.734 \\
1.000 \\
.420\end{array}$ & $\begin{array}{r}.251 \\
.069 \\
.377 \\
.420 \\
1.000\end{array}$ \\
\hline Sig. (1-tailed) & $\begin{array}{l}\text { Contagion } \\
\text { Sociallsolation } \\
\text { relatives } \\
\text { friends } \\
\text { Professors }\end{array}$ & $\begin{array}{l}.000 \\
.284 \\
.181 \\
.007\end{array}$ & $\begin{array}{l}.000 \\
.453 \\
.340 \\
.253\end{array}$ & $\begin{array}{l}.284 \\
.453 \\
.000 \\
.000\end{array}$ & $\begin{array}{l}.181 \\
.340 \\
.000 \\
.000\end{array}$ & $\begin{array}{l}.007 \\
.253 \\
.000 \\
.000\end{array}$ \\
\hline
\end{tabular}

a. Determinant $=.211$

Table 1: Correlation matrix

Total Variance Explained

\begin{tabular}{|c|c|c|c|c|c|c|c|c|c|}
\hline \multirow[b]{2}{*}{ Component } & \multicolumn{3}{|c|}{ Initial Eigenvalues } & \multicolumn{3}{|c|}{ Extraction Sums of Squared Loadings } & \multicolumn{3}{|c|}{ Rotation Sums of Squared Loadings } \\
\hline & Total & $\%$ of Variance & Cumulative \% & Total & $\%$ of Variance & Cumulative $\%$ & Total & $\%$ of Variance & Cumulative $\%$ \\
\hline 1 & 2.071 & 41.419 & 41.419 & 2.071 & 41.419 & 41.419 & 1.747 & 34.940 & 34.940 \\
\hline 2 & 1.586 & 31.715 & 73.134 & 1.586 & 31.715 & 73.134 & 1.556 & 31.122 & 66.062 \\
\hline 3 & .693 & 13.869 & 87.003 & .693 & 13.869 & 87.003 & 1.047 & 20.940 & 87.003 \\
\hline 4 & .438 & 8.759 & 95.762 & & & & & & \\
\hline 5 & .212 & 4.238 & 100.000 & & & & & & \\
\hline
\end{tabular}

Table 2: Total variance explained

Rotated Component Matrix ${ }^{a}$

\begin{tabular}{|l|c|c|c|}
\hline \multirow{2}{*}{} & \multicolumn{3}{|c|}{ Component } \\
\cline { 2 - 4 } & 1 & 2 & 3 \\
\hline Contagion & & .839 & \\
Sociallsolation & & .918 & \\
relatives & .940 & & .924 \\
friends & .884 & & .924 \\
Professors & & & \\
\hline
\end{tabular}

Extraction Method: Principal Component Analysis.

Rotation Method: Varimax with Kaiser Normalization.

a. Rotation converged in 4 iterations.

Table 3: Rotated component matrix

Based on the table 2 and table 3, the following graph which is called as Scree Plot is plotted to know the number of factors which is available in the analysis.

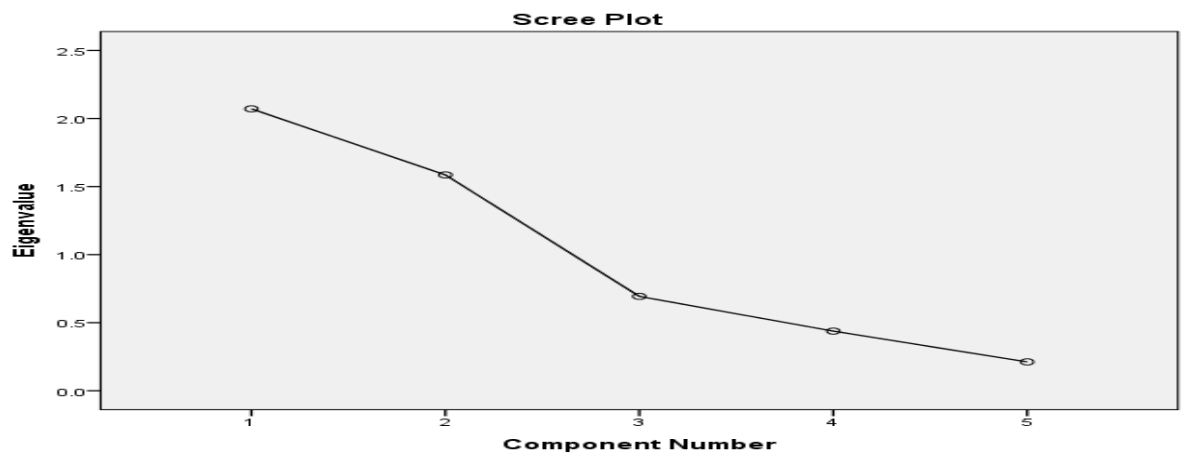

Graph 1. Scree Plot

From the above graph of Scree plot 1, it can be concluded that the factors having the Eigen values more than 1 have to be considered. This study determines 3 factors.

Interpretation (From Table 2)

From the Table 2 of Component Matrix, it can be seen that the following factors can be classified as follows:

Factor 1 
Relationship with family

Relationship with friend

Factor 1 can be renamed as Connection

Factor 2

Contagion

Social isolation

Factor 2 can be termed as Optimism

Factor 3

Relationship with professors and stakeholders in associated college

Factor 3 can be renamed as Positive institutions

With the results of the statistical analysis, coupled with the formal and informal online discussions with the graduate and post-graduate students in Mumbai it can be concluded that the important stressors they face are connected to lack of connection in form of relationship issues with family and friends; lack of optimism in form of fear of contagion or social isolation; lack of presence of positive institutions in form of relationship with professors and different stakeholders in the HEI they are associated with. A major part of their personal and professional effectiveness will involve handling the emotional responses of self and other stakeholders and so it is essential that they get an equipped with emotional intelligence psychosocial variables. (Lima et.al, 2020)

\section{Findings, Discussions, and Implications}

The role of adversity, stress, and negative life events within the genesis of mental state has been recognized since the dawn of psychiatry. The character and strength of the adversity might be large or small and therefore the individual may or might not succumb to subsequent mental disease. That's the individual's reaction to the stressor and their subsequent adaption (or lack of adaption) is extremely idiosyncratic and contextualized (Armstrong et.al, 2011). Specifically, a person may adapt to a selected stressor or negative life event but fail to adapt to a different one. Thus, it absolutely was noted that not all individuals exposed to adversity and negative life events persist to develop a psychological state and have poor outcomes.

Moreover, it had been apparent that some individuals could suffer the foremost distressing negative events or situations and recover or maybe prosper after the adversity. Thus, it became seeming that the phenomenon of resilience had a protective effect for a few individuals. Hence, the study of resilience began. This text reviews research on resilience over the decades so as to describe the potential future focuses for resilience research and positing.

Proposed model: 7 psychosocial variables to deal with the stressors (Dr. Karen et.al,2003)

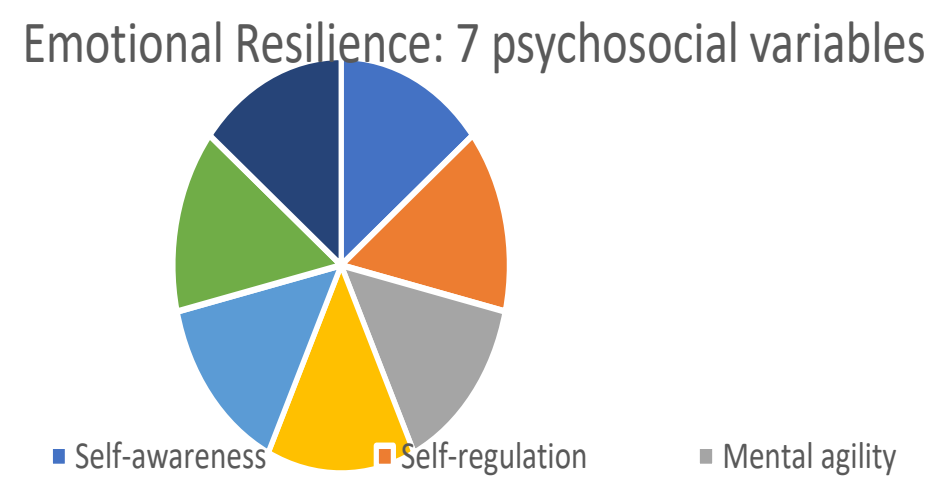

\section{Self-awareness}

Self-awareness is the ability to specialize in yourself and the way your actions, thoughts, or emotions do or do not align along with your internal standards. If you are extremely self-conscious, you'll objectively appraise yourself, manage your emotions, align your behavior along with your values, and perceive properly how others understand you. 
Self-regulation

Self-regulation is that the ability to watch and accomplish your energy states, emotions, feelings, and actions in ways in which are adequate and produce positive results like well-being, and learning.

Mental agility

Mental agility indicates the flexibility of a person to think, learn and quickly absorb new information, systems, and processes, in other words, it stands for the way well our mind can comply with new circumstances.

Optimism

The term derives from the Latin optimum, meaning "best". Being optimistic, within the meaning of the word, is defined as expecting the simplest possible outcome from any given situation. This is often usually said in psychology as dispositional optimism. Optimism may be a knowledge characterized by hope and confidence in success and a positive future. Optimists are those that expect good things to happen, where pessimists instead predict unfavorable outcomes. Optimistic attitudes are connected to variety of advantages, including higher coping skills, lower stress levels, higher physical health, and better persistence when following goals.

Connection

Families with close ties to friends, family, and community groups are likely to own a tougher sense of safety and sense of belonging. These children are more likely to own durable morals and are less likely to hunt out alternative destructive behaviors. In our groups, we foster a way of have its place and we discuss ways your children can strengthen their ties by being an honest friend, a caring loved one, and a vital community member.

Self-efficacy

According to Albert Bandura, self-efficacy is "the confidence in one's capabilities to arrange and execute the courses of action required to accomplish prospective situations." Self-efficacy may be a person's confidence in his or her capability to achieve a specific situation. Bandura described these beliefs as determinants of how people think, behave, and feel

Positive institutions

Positive institutions are defined as "establishments and measured practices in culture or civilization that serve to uplift and mature our highest human assets, combine and increase those strengths, and refract our highest assets outward in world promoting ways leading, eventually, to a world of fullspectrum flourishing.

Limitations

The current study is limited as generalization of the result is difficult as data is collected only from graduate and post-graduate students from Mumbai. The confidentiality with respect to names of respondents from whom data is obtained is also a limitation as the colleges to which respondents are associated and respondents requested for the confidentiality.

\section{Initiatives of Government of India, Ministry of HRD}

In the present study we also document some of the initiatives of the Government of India, taken with respect to starting a website and helpline is to safeguard the mental health of the school / college students to cope effectively caused due the stress of the pandemic and lockdown. The constant coverage of news regarding the pandemic has resulted in a range of responses, particularly for students who may have been the victims, or their family members were affected by the virus. Their response could affect mental and physical health and wellbeing.

\section{Scope of the Research}

The scope of the future research is to test if the proposed structured model suggested in this research study which integrates the 7 psychosocial variables of emotional resilience do impact the personal and professional effectiveness by means of appropriate statistical tool. The longitudinal time series studies can be conducted to check the practical application of the proposed model in HEI in India and globally also so that the findings of the study can be generalized for education sector 


\section{Conclusion}

The findings of the research under study have several practical implications for counselling psychologists, academicians, parents, life coaches handling youth and psychological state workers related to the graduate and post graduate education sector. These findings will put them during a better position to style interventions to reinforce resilience in students within the setting of the significance of both optimistic and damaging mental state during the outburst of diseases and other challenges faced in personal life and vocation.

\section{References}

A R Armstrong, R F Galligan, C R Critchley, (2011) Emotional intelligence and psychological resilience to negative life events Personality and Individual Differences, volume 51, issue 3, p. 331 - 336

Ahorsu, D. K., Lin, C. Y., Imani, V., Saffari, M., Griffiths, M. D., and Pakpour, A. H. (2020). The fear of COVID-19 scale: development and initial validation. Int. J. Ment. Health Addict. doi: 10.1007/s11469-020-00 270-8 [Epub ahead of print].

Chen, B., Sun, J., and Feng, Y. (2020). How have COVID-19 isolation policies affected young people's mental health? Evidence from Chinese college students. Front. Psychol. 11:1529. doi: 10.3389/fpsyg.2020.01529

Horesh, D., and Brown, A. D. (2020). Traumatic stress in the age of COVID-19: a call to close critical gaps and adapt to new realities. Psychol. Trauma 12, 331-335. doi: 10.1037/tra0000592

Conway AM, McDonough SC. (2006) Emotional resilience in early childhood: Developmental antecedents and relations to behavior problems. Ann N Y Acad Sci. ;1094(1):272-77. [PubMed] [Google Scholar]

Davidson RJ. Affective style, psychopathology, and resilience: Brain mechanisms and plasticity. Am Psychol. (2000);55(11):1196-214. [PubMed] [Google Scholar]

Galatzer-Levy IR, Huang SH, Bonanno GA. (2018) Trajectories of resilience and dysfunction following potential trauma: A review and statistical evaluation. Clin Psychol Rev; 63:41-55. Back to cited text no. 12

Karen and Andrew, 2003; The Resilience Factor: 7 Keys to Finding Your Inner Strength and Overcoming Life's Hurdles,

Lei L, Huang X, Zhang S, et al. (2020) Comparison of prevalence and associated factors of anxiety and depression among people affected by versus people unaffected by quarantine during the COVID-19 epidemic in southwestern China. Med Sci Monit. 2020;26: e924609. [PMC free article] [PubMed] [Google Scholar]

Lima CKT, Carvalho PMM, Lima IAAS, et al. (2020) The emotional impact of Coronavirus 2019-nCoV (new Coronavirus disease) Psychiatry Res. :287. [PMC free article] [PubMed] [Google Scholar]

Fiorillo, A., and Gorwood, P. (2020). The consequences of the COVID-19 pandemic on mental health and implications for clinical practice. European Psychiatry, 63, 1-4. 10.1192/j.eurpsy.2020.35

Lazarus, R. S., and Folkman, S. (1984). Stress, Appraisal and Coping. New York, NY: Springer.

Margaritis I, Houdart S, El Ouadrhiri Y, Bigard X, Vuillemin A, Duche P. (2020) How to deal with COVID-19 epidemic-related lockdown physical inactivity and sedentary increase in youth? Adaptation of Anses' benchmarks. ; 78:52.

Maria Clelia Zurlo1*, Maria Francesca Cattaneo Della Volta1 (October 2020),2 and Federica Vallone1,2COVID-19 Student Stress Questionnaire: Development and Validation of a Questionnaire to Evaluate Students' Stressors Related to the Coronavirus Pandemic Lockdown, Frontiers in psychology

OECD Report (June 2020): Youth and Covid19: Response, Recovery and Resilience. Accessed on 27th February 2021. https://www.oecd.org/coronavirus/policy-responses/youth-and-covid-19-response-recovery-and-resiliencec40e61c6/

Sahu, P. (2020). Closure of Universities Due to Coronavirus Disease 2019 (COVID-19): impact on Education and Mental Health of Students and Academic Staff. Cureus 12:e7541. doi: 10.7759/cureus.7541

Taylor, S., Landry, C., Paluszek, M., Fergus, T. A., McKay, D., and Asmundson, G. J. (2020). Development and initial validation of the COVID Stress Scales. J. Anxiety Disord. 72:102232. doi: 10.1016/j.janxdis.2020.102232

World Health Organization (WHO) Statement to the press by Dr Hans Henri P. Kluge, WHO Regional Director for Europe. Mental health and psychological resilience during the COVID-19 pandemic. Mar 27, 2020. Available from:

http://www.euro.who.int/en/health-topics/health-emergencies/coronavirus-covid19/news/news/2020/3/mental-health-and-psychological-resilience-during-the-covid-19-pandemic.

World Health Organization. Coronavirus disease 2019 (COVID-19) Situation Report- 72, 2020. Available at: https://www.who.int/docs/default-source/coronaviruse/situation-reports/20200401-sitrep-72-covid-19.pdf.

Zurlo Maria Clelia Zurlo, Cattaneo Maria Francesca, Volta Cattaneo Della, Vallone Federica Vallone (2020) COVID19 Student Stress Questionnaire: Development and Validation of a Questionnaire to Evaluate Students' Stressors Related to the Coronavirus Pandemic Lockdown . DOI=10.3389/fpsyg.2020.576758 
Zurlo, M. C., Cattaneo Della, Volta, M. F., and Vallone, F. (2017). Factor structure and psychometric properties of the Fertility Problem Inventory-Short Form. Health Psychol. Open 4:2055102917738657.

doi: $10.1177 / 2055102917738657 \backslash$

Dr. Pravat Kumar Jena (2020), Impact of COVID-19 on education in India, International journal of current research, ISSN - 0975-833X

United Nations Educational, Scientific and Cultural Organization (2020).Education: From Disruption to Recovery. Available online at: https://en.unesco.org/covid19/educationresponse (accessed September 1, 2020).

Brooks, S. K., Webster, R. K., Smith, L. E., Woodland, L., Wessely, S., Greenberg, N., et al. (2020). The psychological impact of quarantine and how to reduce it: rapid review of the evidence. Lancet 395, 912-920. doi: 10.1016/S0140-6736(20) 30460-8

Xiang, Y. T., Yang, Y., Li, W., Zhang, L., Zhang, Q., Cheung, T., et al. (2020). Timely mental health care for the 2019 novel coronavirus outbreak is urgently needed. Lancet Psychiatry 7, 228-229. doi: 10.1016/S2215-0366(20)30046-8

Fredrickson BL. (1998) What good are positive emotions? Review of General Psychology: Special Issue: New Directions in Research on Emotion.2:300-319. [PMC free article] [PubMed] [Google Scholar]

Infurna FJ, Luthar SS. (2016) Resilience to major life stressors is not as common as thought. Perspect Psychol Sci; 11:175-94. Back to cited text no. 14

28. ILO Report - ILO Monitor $=$ Covid 19 and the world of work 2nd edition April 2020. https://www.ilo.org/wcmsp5/groups/public/---dgreports/--dcomm/documents/briefingnote/wcms_740877.pdf 